\title{
Modelling terrain for wildfire purposes
}

\author{
$\underline{\text { R.H.D. McRae }}^{\text {a }}$ \\ ${ }^{a}$ School of Science, UNSW Canberra, Australia \\ Email: r.mcrae@adfa.edu.au
}

\begin{abstract}
Prediction of wildfire behaviour requires data on terrain. Traditionally this involves slope for altering headfire rate of spread, and aspect, which is compared to wind direction to derive overall fire spread vectors. This works well for steady-state wildfires and is embedded in all predictive models in use. Climate change is producing an ever-increasing incidence of extreme wildfires, which couple with the atmosphere above and form blow-up fire events. Some of the principal causes of the coupling require a more detailed analysis of terrain geometry.
\end{abstract}

This paper is derived from earlier work to develop a predictive model for lightning-ignition-prone lands. For this, Shuttle Radar Topography Mission digital elevation models were used, with a key step being the derivation of the meso-scale elevation residual (MSER), the difference between the elevation and the locally averaged elevation.

In terrain analysis, for any given point of interest, the average, maximum and minimum values within a $1500 \mathrm{~m}$ radius are derived using desktop GIS packages. The difference between pairs of these values (including the actual elevation) allows estimation of:

- Landform exposure (actual minus average, the MSER); high values indicate exposure; low values indicate entrenchment; and near zero values indicate lightning-ignition potential.

- Landscape ruggedness (maximum minus minimum); low values (flat) suggest elliptical fires; medium values (undulating) suggest slope affected runs; and high values (rugged) suggest dominance of terrain interactions with the weather.

- Wind regime (maximum minus actual) indicate dominant air flows: low values indicate prevailing winds; medium values show lee-eddy winds as well; and high values suggest wind channelling as well.

- Drainage impairment (actual minus minimum) indicating potentials for cold air drainage and waterlogged soil.

- Vorticity-driven lateral spread potential: can be modelled using first or second derivative of elevation. This is now known to be a cause of many major blow-up events in rugged landscapes.

There is a need to tune the resolution of the digital elevation model in use to the scale of the fire. This requires parameterisation of the local landforms. For example, escalated wildfires in rugged terrain are shown to be relatively insensitive to slope values. The required equations and interpretation of outputs are presented in this paper, along with a worked example.

A proper understanding of both terrain data and the greater insights into fire behaviour that it gives have become essential for keeping ahead of the imperatives caused by the influence of climate change on wildfire risks.

Keywords: Terrain, vorticity-driven lateral spread, wind regime, lightning ignitions, ruggedness 


\section{INTRODUCTION}

Most fire behaviour models in use incorporate weather, fuel, and terrain inputs to produce a deterministic prediction of a fire's spread and intensity. Models based on systems such as the McArthur Forest Fire Danger Indices (FFDI, as reviewed in Sharples, 2008 \& Sharples, et al., 2009) assume a quasi-steady-state spread, and produce a single output for any set of inputs.

Rules-of-thumb are used to include the effect of slope - such as doubling the rate of spread for every ten degrees of upslope. Sharples (2008) reviewed aspects of this. Sharples, et al. 2010 \& $2017 \mathrm{~b}$ showed how complex wind-terrain interactions can be. Models such as Wind Ninja (http://firelab.github.io/windninja/) are used operationally to analyse the way that wind flows over or around the terrain. Detailed Computational Fluid Dynamic models can also be used to model wind flow, but their computation overheads mostly prevent their operational use. There are other impacts of terrain on wildfire dynamics (discussed below), and these are increasingly being used operationally. This paper aims to review a methodology for utilizing datasets that model these impacts.

\section{DATA}

The analyses used Shuttle Radar Topography Mission data at a nominal $0.0003^{\circ}$ or $30 \mathrm{~m}$ resolution. The packaged data were accessed through Geoscience Australia (http://www.ga.gov.au/scientific-topics/nationallocation-information/digital-elevation-data ).

\section{ANALYSIS:}

All the steps described here have been conducted in MapInfo. Equivalent steps are available in ESRI ArcGIS and other desktop GIS systems.

Most wildfire modelling applications require data on elevation, slope, and aspect. McRae (1992) showed how additional useful information can be extracted from a Digital Elevation Model (DEM) by comparing the native resolution DEM to one rescaled to a $1500 \mathrm{~m}$ resolution DEM. The difference is termed the meso-scale elevation residual (MSER). The rescaling parameter value was retained for this work.

\subsection{Ingestion}

The DEM was provided as one square degree tiles in the WGS84 spheroid. The analysis domain, DOM, is defined as a polygon and used to patch and trim the SRTM tiles as required. The resulting raw DEM is called DOM_DEM. Regional analyses can be done in metres on a Transverse Mercator projection with resolution set to $200 \mathrm{~m}$, or, for extensive analyses, in degrees in the WGS84 projection with resolution set to $0.002^{\circ}$. Fine-scale analyses can have resolutions as low as $30 \mathrm{~m}$. This raster grid is then exported as a set of points. Domain edge artefacts due to incompletely satisfying the $1500 \mathrm{~m}$ search radius for peripheral points need to be masked out.

\subsection{Modelling}

Analyses are run that step through each exported point and examine all other points within a $1500 \mathrm{~m}$ radius neighbourhood, and then extract the minimum, maximum and average elevation values. Three output grids result, with parameters that match those of DOM_DEM: DOM_Min, DOM_Max and DOM_Avg.

Examples of these are shown in Figure 1 (A) to (D).

\subsection{Outputs}

Additional grids are produced using a grid calculator:

- DOM_MSER=DOM_DEM - DOM_Avg

- DOM_Range = DOM_Max-DOM_Min. DOM_Rugged is a classified form of DOM_Range.

- DOM_Wind = DOM_Max - DOM_DEM

- DOM_Drainage $=$ DOM_DEM - DOM_Min

- DOM_VLS = positive second differential of elevation with respect to distance, times the sign of the MSER, filtered.

Figure 2 shows the relationship between the inputs. Examples of these outputs are shown in Figure 1 (E) to (I) and in Figure 3. 


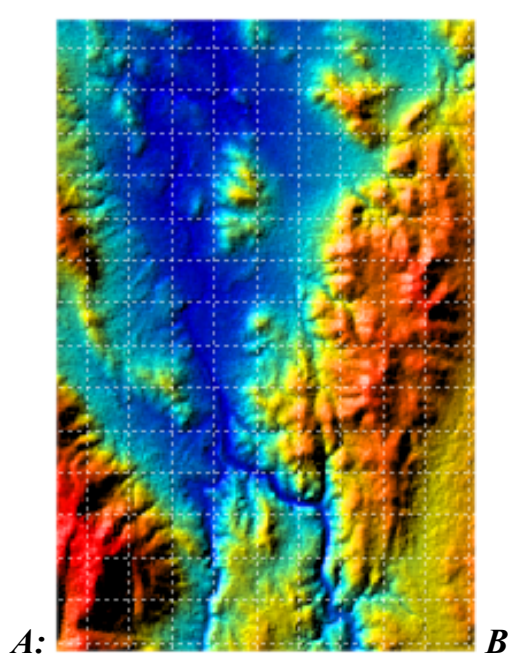

A:

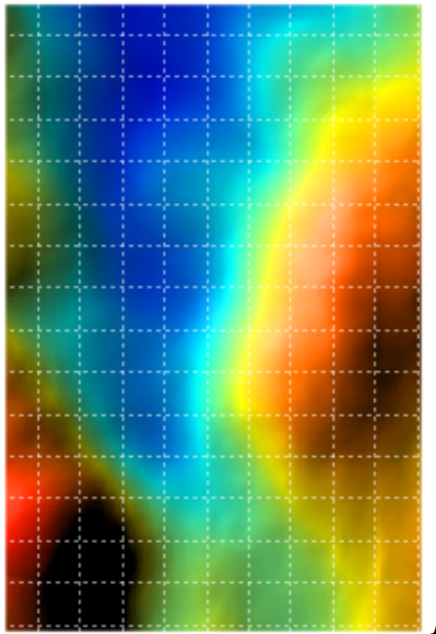

D:

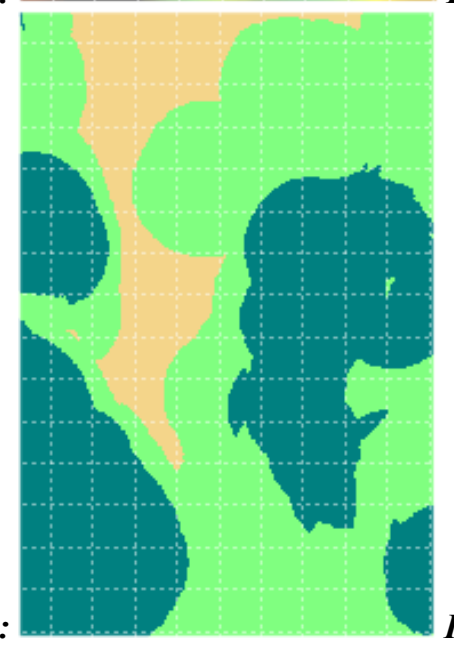

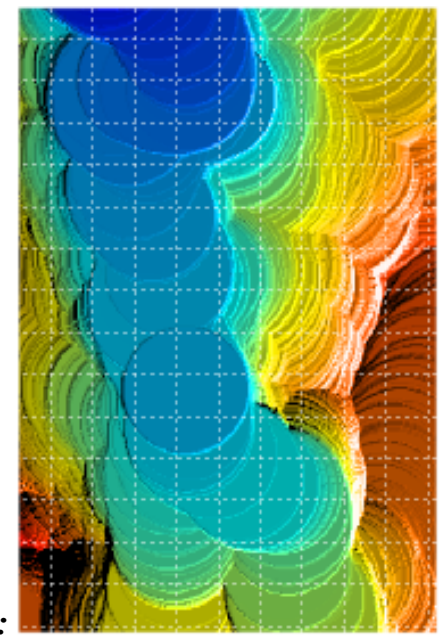

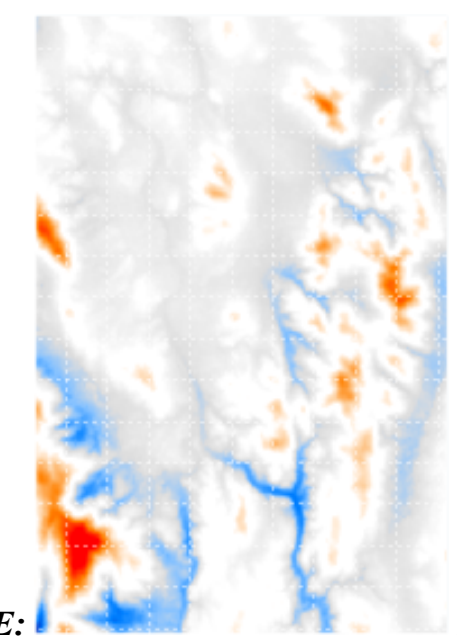

$E:$

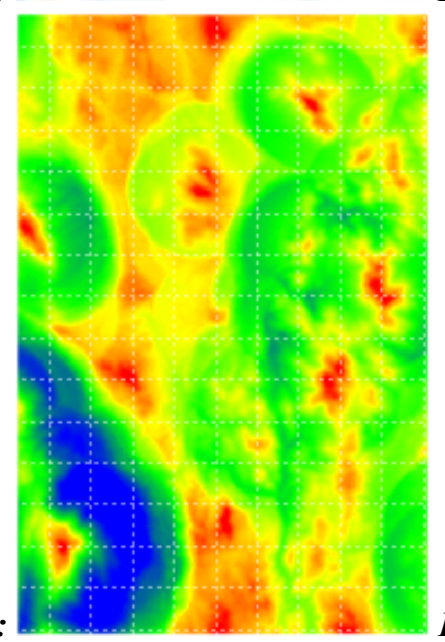

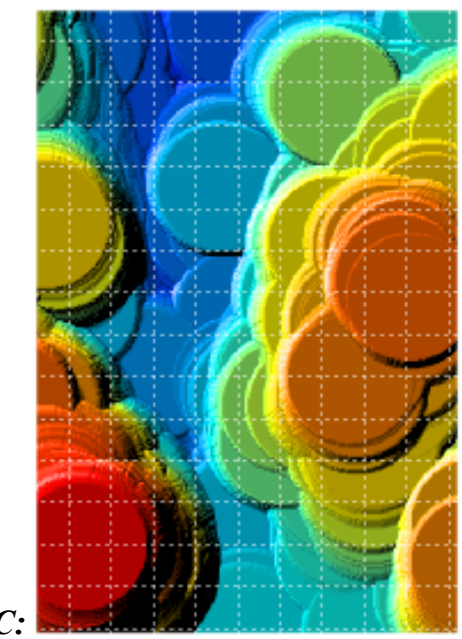
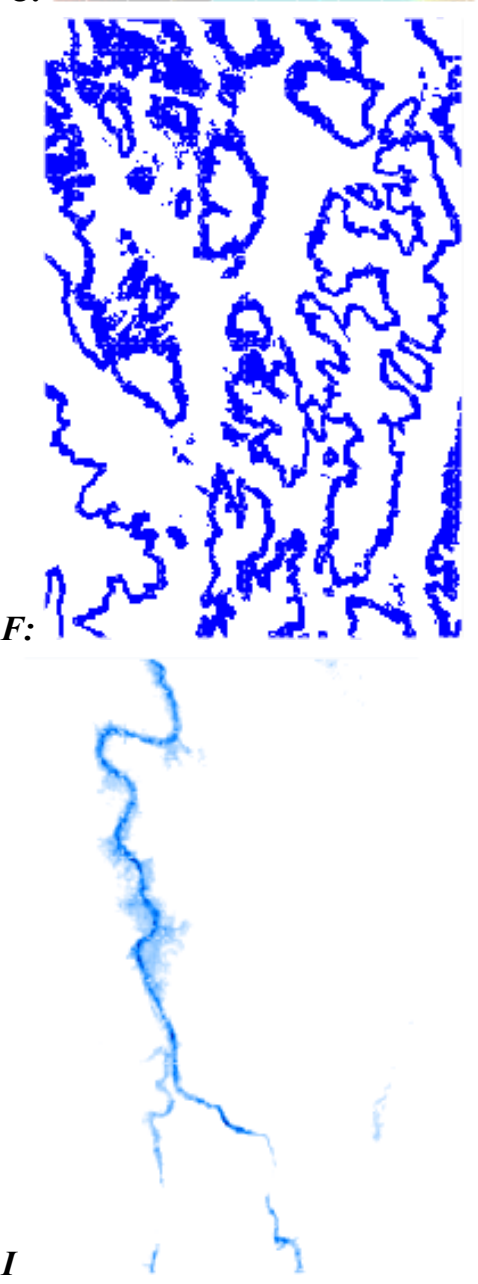

Figure 1. Examples of the terrain grids, around Lanyon, ACT (domain=LANYON). (A) LANYON_DEM, (B) LANYON_Min, (C) LANYON Max, (D) LANYON Avg, (E) LANYON MSER, (F) LANYON NII, (G) LANYON Rugged, (H) LANYON Wind, (I) LANYON Drainage. A $1 \mathrm{~km}$ grid is shown. In panels A to D, elevation: blue $=500 \mathrm{~m}$, Yellow $=700 \mathrm{~m}$, orange $=900 \mathrm{~m}$ and above. In panel E, MSER: orange = exposed, blue $=$ incised. In panel F: blue $=$ areas prone to lightning ignition. In panel G: orange $=$ flat, light green $=$ undulating, dark green $=$ rugged. In panel $\mathrm{H}$, wind regime: orange $=$ prevailing, yellow $=$ also lee eddies, blue $=$ also wind channelling. In panel I: dark blue $=$ incised drainage, light blue $=$ floodplain . 


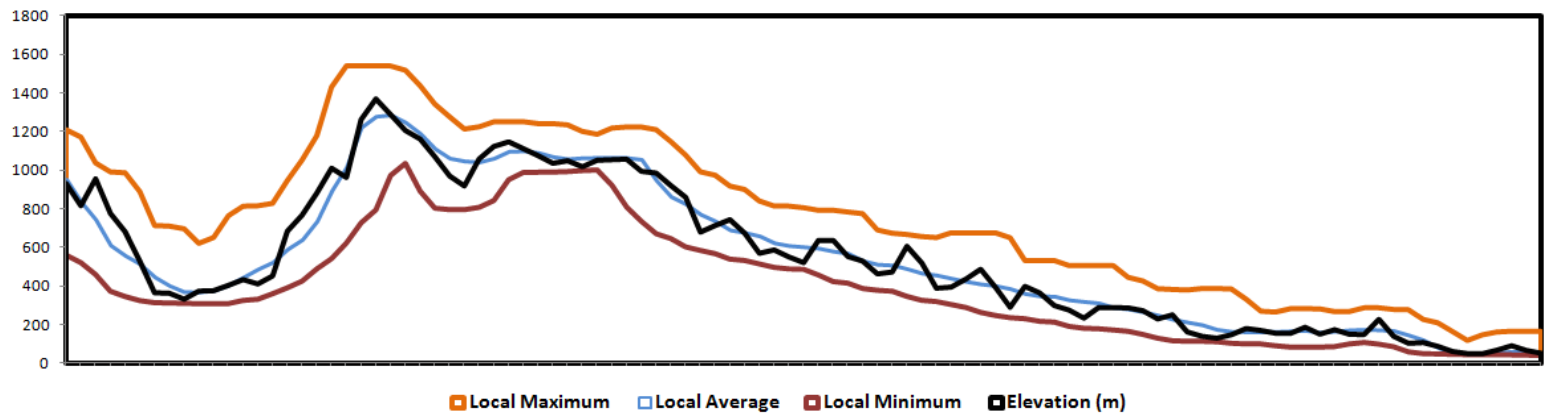

Figure 2. A cross-section, showing the terrain elements discussed above. This is from an area of rugged terrain in NE NSW. The actual elevation is shown by the heavy black line. The minimum and maximum elevations are shown by brown and orange lines, respectively. Note how they bracket the actual value. As this is a one-dimensional cross-section, it may not pick up the neighbourhood values that determine the extremes seen in the orange lines. The average elevation, called the macro-scale elevation, is shown by the blue line.

\subsection{Uses}

Key intended uses for the grids are discussed below.

Table 1. DOM_MSER:

\begin{tabular}{ccl} 
Class & Values & Interpretation \\
\hline Exposed & Over $100 \mathrm{~m}$ & $\begin{array}{l}\text { Exposed sites, including hilltops and ridgetops. Good visibility and } \\
\text { good radio coverage. Drier fuels due to more solar heating. }\end{array}$ \\
Entrenched & Under $-100 \mathrm{~m}$ & $\begin{array}{l}\text { Entrenched or incised sites, including gullies, gorges, and some lower } \\
\text { slopes. Poor visibility and poor radio coverage. Moister fuels. }\end{array}$ \\
$\begin{array}{ccc}\text { Lightning } \\
\text { Agnition prone }\end{array}$ & $\begin{array}{c}\text { Between }-20 \mathrm{~m} \text { and through mid- to upper-slopes and through many saddle points } \\
\text { (as seen in the left-most quarter of Figure 2) defines the area prone to } \\
\text { lightning ignitions. See McRae, 1992. }\end{array}$
\end{tabular}

Table 2. DOM_Range: Used thematically as Ruggedness, DOM_Rugged.

\begin{tabular}{ccl} 
Class & Values & Interpretation \\
\hline Flat & Under $150 \mathrm{~m}$ & Generally elliptical fire spread. \\
Undulating & $150 \mathrm{~m}$ to $300 \mathrm{~m}$ & Fire spread significantly affected by upslope and downslope runs. \\
Rugged & Over $300 \mathrm{~m}$ & $\begin{array}{l}\text { Fires dominated by weather }- \text { terrain interactions. Operational } \\
\text { experience shows that escalated fires are not extinguished in rugged } \\
\end{array}$ \\
& $\begin{array}{l}\text { landscapes, rather they are suppressed when they leave or when it } \\
\text { rains. }\end{array}$
\end{tabular}

Table 3. DOM_Wind:

\begin{tabular}{ccl} 
Class & Values & Interpretation \\
\hline $\begin{array}{c}\text { Prevailing } \\
\text { wind }\end{array}$ & Under50 $\mathrm{m}$ & Flat or exposed ground with prevailing winds. \\
$\begin{array}{c}\text { Lee-eddy } \\
\text { prone }\end{array}$ & $50 \mathrm{~m}$ to $240 \mathrm{~m}$ & $\begin{array}{l}\text { Mid- to upper- slopes. As above but with lee-slope eddy winds when } \\
\text { Wind }\end{array}$ \\
$\begin{array}{l}\text { conditions are suitable: winds over } 25 \mathrm{~km} / \mathrm{hr} \text { and normal to lee slope. } \\
\text { channelling }\end{array}$ & Over $240 \mathrm{~m}$ & $\begin{array}{l}\text { Linear, deeply incised valleys. As above but with wind channelling } \\
\text { when conditions are suitable: winds differ from valley orientation by } \\
\text { an angle of up to } 40^{\circ} .\end{array}$
\end{tabular}

DOM_Drainage: Values less than $5 \mathrm{~m}$ indicate low-lying lands. These have poor drainage and tend to collect cold-air drainage overnight (McRae \& Sharples, 2011). The fog risk may impact fire aviation.

DOM_VLS: Shows sites where, if a fire enters the lee-eddy wind separation line on a ridge or spur then it can spread rapidly laterally. Thematic colouring can show the main wind direction for which any sites could develop VLS (plus or minus $40^{\circ}$ ). 


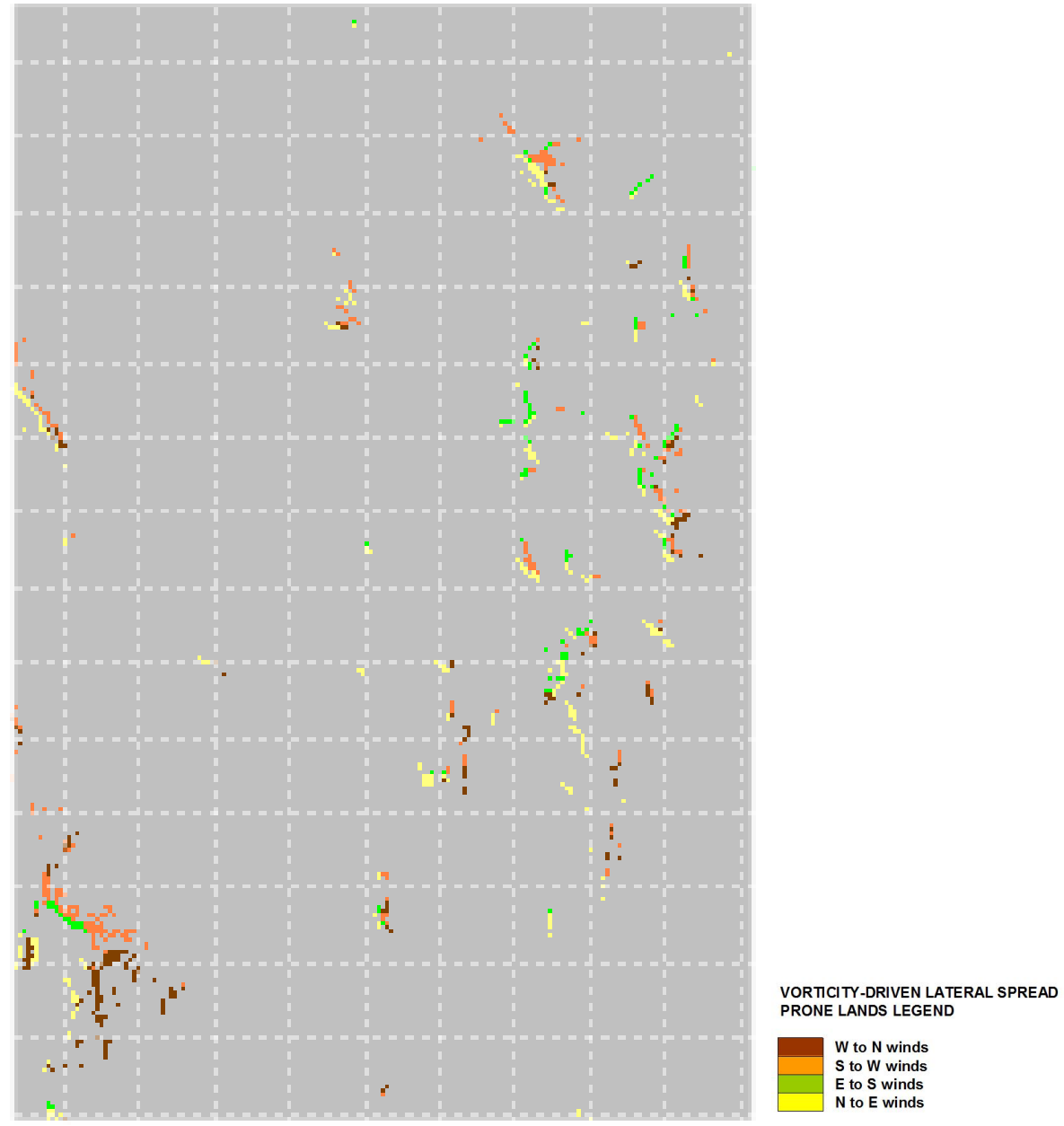

Figure 3. LANYON_VLS. The colours represent wind directions able to initiate VLS, visible in areas that satisfy a model using the second differential of elevation with respect to distance and high MSER.

\subsection{Scale Dependence}

McRae 1992 showed how the notion of scale dependence can be explicitly used to determine where lightning ignitions tend to occur. McRae 1997 showed how fire spread modelling is intrinsically scale-dependent and provided an equation based on landform metrics that can be used for assessing the performance of a spread model.

$$
M V_{D}=M P V \times\left(1-\exp \left(\frac{-2700 \times A}{W \times M P V \times \sqrt{D}}\right)\right)
$$

Where: $\mathrm{D}=$ scale of $\mathrm{DEM}, \mathrm{MV}_{\mathrm{D}}=$ maximum allowable value at $\mathrm{D}, \mathrm{MPV}=$ maximum possible value (e.g., $90^{\circ}$ for slope), $\mathrm{A}=$ amplitude - typical range of local values, $\mathrm{W}=$ wavelength - typical distance between repeating cycles. A rule-of-thumb is that $\mathrm{D}$ should be $1 / 20^{\text {th }}$ of the headfire width.

For example, some possible values for slope for two scales and four landforms are given in the Table below:

Table 4. Landform scaling parameters (McRae 1997).

\begin{tabular}{lllll} 
Land unit & $\mathrm{A}(\mathrm{m})$ & $\mathrm{W}(\mathrm{m})$ & $\mathrm{MV}_{50}$ & $\mathrm{MV}_{200}$ \\
\hline Montane & 1000 & 6000 & 46 & 27 \\
Plateau & 300 & 3000 & 31 & 17 \\
Dunefield & 50 & 5000 & 4 & 2 \\
Plain & 10 & 10000 & 0 & 0 \\
\hline
\end{tabular}


Notably, this showed how the effect of slope on a fire's spread is a function of the fire size. In montane terrain, switching from a DEM with $\mathrm{D}=200 \mathrm{~m}$ to one with $\mathrm{D}=50 \mathrm{~m}$ may result in a $70 \%$ increase in slope values. This should not be automatically used to increase slope-affected rate of spread by $62 \%$, as inferred by FFDI, rather D must be set to a value appropriate to the scale of the fire. Slope effects are significant for small fires and decrease as a fire escalates. This fire scale dependence validates the rule used by Fire Behaviour Analysts for large fires of "turning off slope" (Laurence McCoy, NSW Rural Fire Service, pers comm.).

\section{APPLICATION}

Figure 1 shows examples of the terrain depiction layers for a domain near Lanyon, ACT (LANYON). From this we can deduce:

- There is a system of prominent hilltops, that hold communication towers, a fire tower, and other infrastructure. Terrain analysis puts those sites into a useful context.

- Lightning ignition prone areas ramify through the whole domain and are more likely in rugged areas.

- $\quad$ Parts of the domain are rugged, and for an escalated fire, containment within those is not practical. The ruggedness analysis shows where viable options for containment might begin.

- Wind regimes are very variable. In particular, LANYON_MSER shows as blue a deep lower-slope area in the south-west which is also seen as a large blue area in LANYON_Wind; the latter is an effective barrier to the spread of large wildfires (as occurred in 1939, $2003 \& 2020$ ) due to the complexity of wind flow.

At present the outputs are presented as thematic maps. Fire Behaviour Analysts can use these to assess potential issues with fire behaviour. They are not generally input to operational fire behaviour models at present.

The Blow-Up Fire Outlook (BUFO) model (McRae \& Sharples 2013 \&2014) includes questions about the presence of a rugged landscape (Question 3) and of VLS prone lands (Question 7). These are addressed using the procedures in this paper.

\section{DISCUSSION}

While most fire analysts are primarily interested in elevation, slope and aspect, there is a lot more information that can be derived from a DEM.

NSW State Coroner Dillon (2015) recommended that fire behaviour predictions indicate facts that may affect predictions, including VLS. Implementing these in fire prediction reports would be aided by a more detailed understanding of terrain (Sharples, et al., 2017a).

BUFO basically addresses deep flaming in an unstable atmosphere. Deep flaming is where a fire shifts from linear fire fronts to large tracts of land alight at once (as discussed in McRae, et al., 2015 and in Badlan, et al., 2017). Of the seven known causes, VLS and eruptive spread explicitly require terrain analysis, while dense spotting and use of accelerant may reflect the terrain setting.

The number and extent of BUFEs during Black Summer was unprecedented. Peterson, et al., 2021 make a clear case for this, and indicate how important it is to be prepared not just for an increasing frequency of BUFEs, but an accelerating rate of increase. It is essential that all useful tools - be they helicopters, training modules or modelling systems - be effectively utilised to support mitigation of the ensuing risks.

\section{ACKNOWLEDGEMENTS}

The author has no conflict of interest. Much of the work was done for the ACT Emergency Services Agency as a contribution to the HighFire Risk project of the Bushfire Cooperative Research Centre, in collaboration with staff of UNSW Canberra. Data can be acquired from http://www.highfirerisk.com.au/

\section{REFERENCES}

Badlan, R.L., Sharples, J.J., Evans, J.P. \& McRae, R.H.D., 2017. The role of deep flaming in violent pyroconvection. Proceedings 2017 MODSIM Conference, Hobart. 
Dillon, H.C.B., 2015. Findings, Inquiry into fire at Wambelong Camp Ground, Warrumbungles National Park, New South Wales January 2013. State Coroner's Court, Glebe, Sydney.

McRae, R.H.D., 1992. Prediction of Areas Prone to Lightning Ignition. Int. J. Wildland Fire 2: 123-130.

McRae, R., 1997. Considerations on operational wildfires spread modelling. Proceedings, Australian Bushfire Conference, 1997, Darwin.

McRae, R.H.D. \& Sharples, J.J., 2011. Modelling the Thermal Belt in an Australian Bushfire Context. Proceedings, 2011 MODSIM Conference, Perth.

McRae, R.H.D. \& Sharples, J.J., 2013. A process model for forecasting conditions conducive to blow-up fire events. Proceedings, 2013 MODSIM Conference, Adelaide.

McRae, R.H.D. \& Sharples, J.J., 2014. Forecasting conditions conducive to blow-up fire events $C A W C R$ Research Letters, 11, 14-19.

McRae, R H D, Sharples, JJ, Fromm, M., 2015. Linking local wildfire dynamics to pyroCb development. Natural Hazards and Earth Systems Sciences, 15, 417-428.

Peterson, D.A., Fromm, M.D., McRae, R.H.D., Campbell, J.R., Hyer, E.J., Taha, G., Camacho, C.P., Kablick, G.P., Schmidt, C.C. \& DeLand M.T., 2021. The unprecedented pyrocumulonimbus super outbreak in Australia at the dawn of 2020: cause and perspective. npj Clim Atmos Sci 4, 38. https://doi.org/10.1038/s41612-021-00192-9.

Sharples, J.J., 2008. Review of formal methodologies for wind-slope correction of wildfire rate of spread. International Journal of Wildland Fire, 2008, 17, 179-193.

Sharples, J.J., McRae, R.H.D., Weber, R.O. \& Gill, A.M., 2009. A simple index for assessing fire danger rating. Environmental Modelling and Software 24, 764-774.

Sharples, J.J., McRae, R.H.D. \& Weber, R.O., 2010. Wind characteristics over complex terrain with implications for bushfire risk management. Environmental Modelling and Software 25: 1099-1120.

Sharples, J.J., Richards, R., Hilton, J.E., Ferguson, S., Cohen, R.C.Z. \& Thatcher, M., 2017a. Dynamic simulation of the Cape Barren Island fire using the Spark framework. Proceedings 2017 MODSIM Conference, Hobart.

Sharples, J.J., McRae, R.H.D., Simpson, C.C., Fox-Hughes, P. \& Clements, C.B., 2017b. Terrain-Controlled Airflows. Fire Management Today, 75 (1): 20-24. 